\title{
Factors predicting Postnatal Depression immediately after delivery and at 6 weeks : a study from a teaching hospital in southern India
}

\author{
Rajendiren Soundravally \\ Shivanand Kattimani ${ }^{2}$ \\ Anand Aswathi ${ }^{3}$ \\ Aishwarya Say \\ Durairaj Jayalakshmi \\ Haritha Sagili ${ }^{6}$ \\ Siddharth Sarkar \\ ${ }^{1}$ Assistant Professor, Department of Biochemistry, \\ ${ }^{2}$ Assistant Professor, Department of Psychiatry, \\ ${ }^{3,4}$ MSC student, Department of Biochemistry, \\ ${ }^{5}$ Addl. Professor, Department of Obstetrics and Gynaecology, \\ ${ }^{6}$ Assistant Professor, Department of Obstetrics and Gynaecology, \\ ${ }^{7}$ Resident Doctor, Department of Psychiatry, \\ JIPMER, Dhanvantary Nagar, Puducherry 605006. \\ E-mail -drshivanand@gmail.com
}

\begin{abstract}
Longitudinal research on depression in the postpartum period can an opportunity to identify women at risk and treat them promptly if depression develops. The present study aimed to find persistence and predictors of depression in the hospital in south India were assessed for depressive symptoms within 24-48 hours of delivery. They were reassessed at six weeks for depressive symptoms. Demographic and clinical data were recorded and depressive symptoms were measured using Edinburgh Postnatal Depression Scale (EPDS). Logistic regression analysis was carried out to find participated, $316(66.4 \%)$ were screened to be having significant postnatal depressive symptoms as per EPDS (scoring more than 9), at baseline. Of the 103 who followed up at six weeks, significant postnatal depressive symptoms were present in 62 (60.2\%). Low birth weight of the baby, Iow APGAR scores at birth and unemployed status predicted depressive symptoms at baseline. Presence of significant depressive symptoms at baseline were the strongest predictor of persistence of significant depressive postpartum period are present in a considerable proportion of women. These symptoms
\end{abstract} help in understanding the predictors of depressive symptoms. Such information will give postpartum period. In this longitudinal study, women who delivered at a tertiary care predictors of depression at baseline and six weeks. Out of the 476 women who symptoms at six week follow-up.Significant depressive symptoms in the immediate predict presence of depressive symptoms at six weeks postpartum.

Key words: depression, follow-up, predictors, postpartum, postnatal 


\section{INTRODUCTION}

The process of delivery is physiologically and psychologically stressful event for a woman. Hormonal and psychosocial changes accompanying the process of delivery can be strenuous, and so can the additional responsibility of handling a baby [13]. Many of the women develop depressive symptoms as a consequence in the form of baby blues [4]. Depressive symptoms may develop in some of the women during the pregnancy, immediately after the delivery or subsequently at the time of weaning [5]. Presence of postpartum depressive symptoms leads to decreased ability of the mother to take care of the baby, and may adversely affect infant development [6-8]. Hence recognition and treatment of this condition is important from the perspective of the mother and the baby. There are many studies that have evaluated the presence of depressive symptoms in the post-natal period [9-11]. These studies have found depressive symptoms ranging from less than $10 \%$ to over $60 \%$. When the screening for depressive symptoms is done immediately after the delivery of the baby, one is not sure whether is covers the postnatal or antenatal symptoms and also its stability over time. Many symptoms during that time could be due to strain of labour. A few studies have assessed how the depressive symptoms in the immediate post-natal period predict persistence of the same [12-14]. Assessment of the relationship of predictors of persistence of depressive symptoms can be valuable from two aspects. Firstly, it can help to understand in how much proportion, the depressive symptoms remain persistent and are problematic over a period of time. And secondly, it can help identify factors which can be markers for detecting those at risk so that close monitoring can be done and remedial measures can be undertaken. Hence this study assessed depressive symptoms in women who underwent delivery and then followed up at the centre.

\section{METHODOLOGY}

This longitudinal study was conducted in the Department of Obstetrics and Gynaecology of a government tertiary care hospital in Southern India. The hospital provides free treatment facilities and caters mainly to socio-economically weaker patient from the region. After delivery and stabilization, patients are usually sent home over next 4-5 days with a request to follow up at the centre or nearby primary health centres in the vicinity of the patient's home. For the purpose of the present study women who delivered at the centre, able to read in local language (Tamil) were included after taking their informed consent. Those patients with the history of endocrine disturbances, pre-existing psychiatric illness or a neurological disorder or having complications during pregnancy or during delivery were excluded. The information about medical/psychiatric disorders and complications was checked through medical records and by participant self report.

The study was approved by the institute ethics committee. The participants who fulfilled inclusion and exclusion criteria were recruited through purposive sampling. Demographic and delivery related clinical data were obtained. Data included education level, employment status, maternal weight, height and body mass index, haemoglobin level, type of delivery. Information was obtained about the baby, including gender, weight, APGAR scores and any illness detected in the baby immediately postpartum. Presence of depressive symptoms was assessed using Edinburgh Postnatal Depression Scale (EPDS). This scale was chosen as it is a brief and reliable self rated screening instrument. The initial data assessment was conducted within first 24 to 48 hours after the delivery. The patients were thereafter followed up six 
weeks postpartum at the hospital. Depressive symptoms were reassessed using the EPDS at the follow-up. Data collection was done during the period of December 2010 to November 2011.

EPDS is a well validated self reported scale, consisting of 10 statements related to depressive symptoms. Each statement is self-rated for its severity on four point likert scale $(0,1,2$ and 3 ) and six of the questions are reverse scored. Total scores can range from 0 to 30 . This scale has also been validated for detecting postnatal depressive symptoms within the first week of delivery [14]. A validated Tamil version of EPDS was used in the present study [15]. A cut-off score of 9 and above has been found to have sensitivity of $94.1 \%$ and specificity of $90.2 \%$ to detect significant postnatal depressive symptoms which is equivalent to having depressive illness of varying severity, according to the Tamil version of the scale. Confirmation for presence of depressive illness requires further clinical interview by an expert. In this study, we used screen positive for significant depressive symptoms using EPDS as those having scores above cut-off of 9 on EPDS scale.

Descriptive data was represented using frequency, percentages, means and standard deviations. Demographic and clinical variables were compared among those who had significant depressive symptoms to those who did not at baseline and at six weeks. The variables were also compared to find differences between who followed up and who did not. Mann Whitney $U$ was used for comparison for skewed continuous variables and chi-square test was used for categorical data. A p value of less than 0.05 was considered significant. Fisher's exact test was used for categorical analysis when count in any group was less than 5. A multivariate logistic regression with forward Wald method was conducted to find independent predictors of depressive symptoms at baseline and at follow-up. Forward Wald method was used as it is a better determinant for independent predictors when large numbers of variables are put into the regression equation. Similar analysis was also conducted to find independent predictors of retention. The models were confirmed by backward Wald method of logistic regression. Nagelkerke $\mathrm{R}^{2}$ was used to find an estimate of the robustness of the model.

\section{RESULTS}

A total of 476 women were included in the study at baseline. The mean age of the sample was 23.6 years ( \pm 3.0 years) with a range of 18 to 37 years. Out of the 476 women, $316(66.4 \%)$ scored above the cut-off of depressive symptoms as per EPDS. The characteristics of the overall sample at the baseline assessment, and those who had depressive symptoms along with those who did not are shown in Table 1. Majority of the participants were educated up to high school, were not employed, were primipara and had a vaginal delivery. Few of the cases were of twin pregnancy $(n=10)$, and some of the neonates had medical/ surgical problems that necessitated intervention $(n=30)$. The APGAR scores at one minute and five minutes had a good degree of correlation among themselves (Kendall tau $=0.928, \mathrm{p}<0.001$ ), and one minute APGAR scores were used for further regression analysis to avoid duplicity of predictors. None of the women reported dissatisfaction with the gender of the baby and only two reported marital discord (not shown in the table).

Table 1 also shows the differences in characteristics between the women who had depressive symptom scores above cut-off versus those who did not have scores above cut-off. The group with depressive symptoms above cut-off had 
greater proportion of not-employed women $\left(x^{2}=4.734, \mathrm{p}=0.030\right)$, twin pregnancy $\left(\mathrm{x}^{2}\right.$ $=5.172, \mathrm{p}=0.019$ ), lower APGAR scores at one minute and five minutes (Mann Whitney $U=20683$ and 20913 respectively, $p<0.001$ for both) and low baby birth weight $(U=19877, p=0.001)$.

Of the 476 women who underwent a delivery at the hospital, 103 followed up at the period of 6 weeks. A comparison of those who followed up versus those who did not is shown in table 2. The two groups were similar on most of the characteristics. Those who followed up differed significantly with those who did not only on age (Mann Whitney $U=16441, p=0.024$ ) with younger aged women less likely to do follow-up.

Table 3 shows the characteristics of the women with and without depressive symptoms as reassessed using EPDSs among the 103 women who followed up at six weeks. Of the 103 women, 62 (60.2\% of the sample) had depressive symptoms above the EPDS cut-off (having postpartum depressive symptoms). Among the variables compared, only presence of depressive symptoms at baseline was significantly different between the two groups. Among the 103 patients at follow-up, 73 had screened positive for depressive symptoms at initial evaluation. But in 14 of these 73 participants, the depressive symptoms were not present when reassessed at six weeks follow-up. The positive predictive value of depressive symptoms for predicting depressive symptoms later on was $80.8 \%$ and the negative predictive value was $90.0 \%$.

The logistic regression analysis is summarized in table 4 . Binary logistic regression analysis suggests that lower birth weight of the baby, lower APGAR score at one minute and unemployed status were predictors of having depressive symptoms at baseline. The model explained about $8.4 \%$ of the variance. A lower haemoglobin level of the mother was the only independent predictor of follow-up status, but the model was very weak (explained about $1.7 \%$ of the variance). When logistic regression was conducted to find predictors of depressive symptoms at follow up, presence of depressive symptoms at the initial assessment emerged as the only independent predictor variable. The model was a good one with Nagelkerke R2 value of 0.626 , explaining about $62.6 \%$ of the variance.

When cut-off scores of 13 were used instead of nine in the validated Tamil version of EPDS, it was seen that $27.3 \%$ of the women had significant depressive symptoms in the immediate postpartum period and $23.3 \%$ at the six weeks follow-up. Logistic regression with the higher cut-offs also suggested that depressive symptoms at baseline was the strong predictor of subsequent depressive symptoms.

\section{DISCUSSION}

The present study suggests that about two thirds of the women have significant depressive symptoms in the immediate postnatal period (within first 24-48 hours after delivery). In the majority of such cases, the depressive symptoms persisted at six weeks follow-up. Low baby weight, low APGAR score and unemployed status predicted depressive symptoms at baseline. The strongest predictor of depressive symptoms at follow-up was the presence of depressive symptoms at baseline.

The rate of depressive symptoms found in the study has been substantially higher than other studies assessing postpartum depressive symptoms 
$[9,16]$. The rates have been higher than reported from other studies from India [17-19]. One of the reasons could be that the present study assessed women in the immediate postpartum period still under the stress of labour. Certain other studies have also found high rates of depressive symptoms in the first week after delivery [20-21], though others have found low rates of depressive symptoms [22-23]. Another possibility for lower scores is the lower cut-off of Tamil version of EPDS used in the present study [15]. The validated Tamil version suggests a lower cut-off core of nine as compared to the score of 13 for the original English version. With the conservative higher cut-offs of 13 on post hoc analysis, only about one fourth of the participants had significant depressive symptoms.

It was seen that a high proportion of patients who had depressive symptoms in the immediate postpartum period continued to have depressive symptoms at six weeks. As in other studies, our study has also found that immediate postpartum depressive symptoms on the continuous scale of EPDS overall correlates with the follow up scores [12-13]. The results are however, differed from a study that found a substantial drop in rates of depressive symptoms at eight weeks follow-up14. Similarly, a Canadian study suggests that only about 30 percent of those who have significant depressive symptoms at baseline continue to have high scores at four to six weeks of follow-up [13]. Though the women who followed up were similar to those who did not in many of the characteristics, selective follow-up of those remaining depressed cannot be ruled out.

In the present study, lower weight of the baby, poor APGAR scores and unemployed status emerged as risk factors for postpartum depressive symptoms. Lower birth weight and poor APGAR scores reflect poor health condition of the baby that might have led to distress and depressive symptoms in the mother. Low birth weight and infant distress may be an independent predictor of maternal depressive symptoms even after adjusting for other variables [10,24-25]. Unemployed status also predicted depressive symptoms in the present sample, possibly reflective of stress related to financial difficulties. Another study had similar findings that noted full time employment to be less frequently associated with depressive symptoms in the postpartum period [26]. Contrary to some studies from the region, our study did not find differences in rates of depressive symptoms according to gender of the new born $[18,27]$. None of the women reported dissatisfaction with the gender of the newborn and only two of the women had reported marital problems. There is a possibility of considerable under-reporting of these. Alternatively, male child preference might not be a major issue in this region, as census reports of a more favourable female to male ratio than in other parts of the country [28].

The findings of the study should be interpreted in the light of the limitations. The sample comprised only of women whose delivery was conducted at a tertiary care hospital. The results cannot be generalized to primary care or community setting. The sample was restricted to those who could read in Tamil and is not applicable to illiterate population. The first assessment was conducted within 48 hours of delivery and EPDS might have captured some symptoms immediately prior to the delivery. However, other studies have also used EPDS within the first week of delivery and have found it to be valid and useful. The present study also studied only selected variables pertinent to the women undergoing a delivery, though an array of other potentially relevant variables could have been studied. The depressive symptoms in the study 
reflect those rated as per EPDS and not based on a structured interview by a psychiatrist. Finally, a limited sample of the participants followed up at the second interview and there was substantial attrition. Despite the limitations, the study has the strengths of using a well validated vernacular version of the most commonly used postpartum depression screening scale. The study also recruited a large number of women at the initial screening period. Though most studies have attempted to find out presence of depressive symptoms about four to eight weeks postpartum, this study assessed depressive symptoms in the immediate postpartum period. The immediate postpartum period is a time when women are readily accessible for assessment and will be in contact with the health care services, and thus close follow up of those at risk can be instituted.

To conclude, the study suggests that postpartum depressive symptoms seem to be present in a substantial proportion of postpartum women. Those with financial distress or poor health condition of the baby are likely to report depressive symptoms more frequently. These depressive symptoms seem to persist in a significant proportion of those women who show depressive symptoms in the initial period. Hence routine assessment of depressive symptoms in the postnatal period may help in early detection and subsequently prompt intervention for these women.

\section{REFERENCES}

1. Bloch M, Daly RC, Rubinow DR. Endocrine factors in the etiology of postpartum depression. Compr Psychiatry 2003;44:234-246.

2. Brummelte S, Galea LAM. Depression during pregnancy and postpartum: contribution of stress and ovarian hormones. Prog Neuropsychopharmacol Biol Psychiatry 2010;34:766-776.

3. O'Hara MW. Postpartum depression: what we know. J Clin Psychol 2009;65:12581269.

4. Wisner KL, Parry BL, Piontek CM. Postpartum depression. N Engl J Med 2002;347:194199.

5. O'Hara MW, McCabe JE. Postpartum depression: current status and future directions. Annu Rev Clin Psychol 2013;9:379-407.

6. Diego MA, Field T, Hernandez-Reif M, Cullen C, Schanberg S, Kuhn C. Prepartum, postpartum, and chronic depression effects on newborns. Psychiatry 2004;67:63-80.

7. McLearn KT, Minkovitz CS, Strobino DM, Marks E, Hou W. Maternal depressive symptoms at 2 to 4 months postpartum and early parenting practices. Arch Pediatr Adolesc Med 2006;160:279-284.

8. Goodman SH, Rouse MH, Connell AM, Broth MR, Hall CM, Heyward D. Maternal depression and child psychopathology: a meta-analytic review. Clin Child Fam Psychol Rev 2011;14:1-27.

9. Klainin P, Arthur DG. Postpartum depression in Asian cultures: a literature review. Int J Nurs Stud 2009;46:1355-1373.

10. Vigod SN, Villegas L, Dennis C-L, Ross LE. Prevalence and risk factors for postpartum depression among women with preterm and low-birth-weight infants: a systematic review. BJOG 2010;117:540-550.

11. Villegas L, McKay K, Dennis C-L, Ross LE. Postpartum depression among rural women from developed and developing countries: a systematic review. J Rural Health $2011 ; 27: 278-288$.

12. Hannah $P$, Adams D, Lee A, Glover V, Sandler M. Links between early postpartum mood and post-natal depression. Br J Psychiatry 1992;160:777-780.

13. Teissèdre $F$, Chabrol H. Detecting women at risk for postnatal depression using the Edinburgh Postnatal Depression Scale at 2 to 3 days postpartum. Can J Psychiatry 2004;49:51-54. 
14. Jardri R, Pelta J, Maron M, Thomas P, Delion P, Codaccioni X, et al. Predictive validation study of the Edinburgh Postnatal Depression Scale in the first week after delivery and risk analysis for postnatal depression. J Affect Disord 2006;93:169-176.

15. Benjamin D, Chandramohan A, Annie IK, Prasad J, Jacob KS. Validation of the Tamil version of Edinburgh postpartum depression scale. J Obstet Gynecol India 2005;55:241-243.

16. Roomruangwong C, Epperson CN. Perinatal depression in Asian women: prevalence, associated factors, and cultural aspects. Asian Biomed 2011:5:179-193

17. Mariam KA, Srinivasan K. Antenatal psychological distress and postnatal depression: A prospective study from an urban clinic. Asian J Psychiatry 2009;2:71-73.

18. Savarimuthu RJS, Ezhilarasu P, Charles H, Antonisamy B, Kurian S, Jacob KS. Postpartum depression in the community: a qualitative study from rural South India. Int J Soc Psychiatry 2010;56:94-102.

19. Dubey C, Gupta N, Bhasin S, Muthal RA, Arora R. Prevalence and associated risk factors for postpartum depression in women attending a tertiary hospital, Delhi, India. Int J Soc Psychiatry 2012;58:577-580.

20. Hau FWL, Levy VA. The maternity blues and Hong Kong Chinese women: an exploratory study. J Affect Disord 2003;75:197-203.

21. Tiwari $A$, Chan $K L$, Fong $D$, Leung $W C$, Brownridge $D A$, Lam $H$, et al. The impact of psychological abuse by an intimate partner on the mental health of pregnant women. BJOG 2008;115:377-384.

22. Abou-Saleh MT, Ghubash R. The prevalence of early postpartum psychiatric morbidity in Dubai: a transcultural perspective. Acta Psychiatr Scand 1997;95:428-432.

23. Pawar G, Wetzker C, Gjerdingen D. Prevalence of depressive symptoms in the immediate postpartum period. J Am Board Fam Med 2011;24:258-261.

24. Tamaki R, Murata M, Okano T. Risk factors for postpartum depression in Japan. Psychiatry Clin Neurosci 1997;51:93-98.

25. Adewuya AO, Fatoye FO, Ola BA, Ijaodola OR, Ibigbami S-MO. Sociodemographic and obstetric risk factors for postpartum depressive symptoms in Nigerian women. J Psychiatr Pract 2005;11:353-358.

26. Miyake $Y$, Tanaka K, Sasaki S, Hirota Y. Employment, income, and education and risk of postpartum depression: the Osaka Maternal and Child Health Study. J Affect Disord 2011;130:133-137.

27. Rodrigues M, Patel V, Jaswal S, de Souza N. Listening to mothers: qualitative studies on motherhood and depression from Goa, India. Soc Sci Med 2003;57:1797-1806.

28. Sex Ratio of India | Female per 1000 male Gender Ratio | Indian Population Census 2011 [Internet]. Available from: http://www.census2011.co.in/sexratio.php.

Acknowledgements - Nil

Conflict of Interest - Nil

Funding - Nil 
Table 1: Characteristics of baseline sample

\begin{tabular}{|c|c|c|c|c|c|}
\hline Variable & & $\begin{array}{l}\text { Overall sample }(\mathrm{A}) \\
\mathrm{N}=476\end{array}$ & $\begin{array}{l}\text { Sample with significant } \\
\text { depressive symptoms (B) } \\
\mathrm{N}=316\end{array}$ & $\begin{array}{l}\text { Sample without } \\
\text { significant depressive } \\
\text { symptoms }(\text { (C) } N=160\end{array}$ & $\begin{array}{l}\text { Comparison (B versus } \\
\text { C) (significance) }\end{array}$ \\
\hline Age & & $23.6( \pm 3.0)$ & $23.6( \pm 3.1)$ & $23.7( \pm 2.9)$ & $U=24805.5(0.736)$ \\
\hline \multirow[t]{2}{*}{ Education } & Up to High school & $348(73.1 \%)$ & 234 & 114 & $x^{2}=0.424(0.515)$ \\
\hline & Above & $128(26.9 \%)$ & 82 & 46 & \\
\hline \multirow[t]{2}{*}{ Employment } & Employed & $61(12.8 \%)$ & 33 & 28 & $x^{2}=4.734(0.030)^{*}$ \\
\hline & $\begin{array}{l}\text { Not employed/ } \\
\text { homemaker }\end{array}$ & $415(87.2 \%)$ & 283 & 132 & \\
\hline \multirow[t]{2}{*}{ Parity } & Primipara & $301(63.4 \%)$ & 207 & 94 & $X^{2}=2.217(0.136)$ \\
\hline & Multipara & $174(36.6 \%)$ & 108 & 66 & \\
\hline \multirow[t]{2}{*}{ Mode of delivery } & Vaginal & $461(96.8 \%)$ & 305 & 156 & $x^{2}=0.335(0.563)$ \\
\hline & Caesarean & $15(3.2 \%)$ & 11 & 4 & \\
\hline \multirow[t]{2}{*}{ Difficult pregnancy } & Yes & $170(35.7 \%)$ & 15 & 155 & $x^{2}=0.694(0.405)$ \\
\hline & No & $306(64.3 \%)$ & 301 & 5 & \\
\hline \multirow[t]{2}{*}{ Twin pregnancy } & Yes & $10(2.1 \%)$ & 10 & 0 & $x^{2}=5.172(0.019)^{*}$ \\
\hline & No & $466(97.9 \%)$ & 306 & 160 & \\
\hline \multicolumn{2}{|c|}{ Recent Hemoglobin level(just before delivery) } & $10.7( \pm 1.3)$ & $10.6( \pm 1.4)$ & $10.7( \pm 1.3)$ & $U=24643.5(0.819)$ \\
\hline \multicolumn{2}{|c|}{ BMI (just before delivery) } & $22.5( \pm 3.3)$ & $22.5( \pm 3.6)$ & $22.6( \pm 2.6)$ & $U=24390.5(0.530)$ \\
\hline \multicolumn{2}{|c|}{ APGAR score at 1 minute } & $7.9( \pm 0.5)$ & $7.8( \pm 0.6)$ & $8.0( \pm 0.3)$ & $U=20683(<0.001)^{*}$ \\
\hline \multicolumn{2}{|c|}{ APGAR score at 5 minutes } & $8.9( \pm 0.4)$ & $8.8( \pm 0.5)$ & $9.0( \pm 0.4)$ & $U=20913(<0.001)^{*}$ \\
\hline \multicolumn{2}{|c|}{ Baby's weight at birth } & $2.8( \pm 0.5)$ & $2.7( \pm 0.5)$ & $2.9( \pm 0.4)$ & $U=19877(0.001)^{*}$ \\
\hline \multirow[t]{2}{*}{ Illness in infant } & Yes & $30(6.3 \%)$ & 20 & 10 & $x^{2}=0.002(0.966)$ \\
\hline & No & $445(93.7 \%)$ & 295 & 150 & \\
\hline \multirow[t]{2}{*}{ Gender of infant } & Male & $222(46.6 \%)$ & 149 & 73 & $x^{2}=0.100(0.752)$ \\
\hline & Female & $254(53.4 \%)$ & 167 & 87 & \\
\hline
\end{tabular}

Shown as mean ( \pm standard deviation) or frequency (percentages), BMI Body Mass Index 
Table 2: Comparison of sample who followed up and who did not follow up

\begin{tabular}{|c|c|c|c|c|}
\hline Variable & & $\begin{array}{l}\text { Followed up } \\
(\mathrm{N}=103)\end{array}$ & $\begin{array}{l}\text { Did not follow up } \\
(\mathrm{N}=373)\end{array}$ & $\begin{array}{l}\text { Comparison } \\
\text { (significance) }\end{array}$ \\
\hline Age & & $23.8( \pm 3.1)$ & $23.0( \pm 2.7)$ & $U=16441(0.024)^{*}$ \\
\hline \multirow[t]{2}{*}{ Education } & Up to High school & $71(14.9 \%)$ & $277(58.2 \%)$ & $x^{2}=1.167(0.280)$ \\
\hline & Above & $32(6.7 \%)$ & $96(20.2 \%)$ & \\
\hline \multirow[t]{2}{*}{ Employment } & Employed & $14(2.9 \%)$ & $47(9.9 \%)$ & $x^{2}=0.071(0.790)$ \\
\hline & $\begin{array}{l}\text { Not employed/ } \\
\text { homemaker }\end{array}$ & $89(18.7 \%)$ & $326(68.5 \%)$ & \\
\hline \multirow[t]{2}{*}{ Parity } & Primipara & $68(14.3 \%)$ & $233(49.1 \%)$ & $x^{2}=0.398(0.528)$ \\
\hline & Multipara & $35(7.4 \%)$ & $139(29.3 \%)$ & \\
\hline \multirow[t]{2}{*}{ Mode of delivery } & Vaginal & $101(21.2 \%)$ & $360(75.6 \%)$ & $x^{2}=0.630(0.541)$ \\
\hline & Caesarean & $2(0.4 \%)$ & $13(2.7 \%)$ & \\
\hline \multirow[t]{2}{*}{ Difficult pregnancy } & Yes & $3(0.6 \%)$ & $17(3.6 \%)$ & $x^{2}=0.543(0.587)$ \\
\hline & No & $100(21 \%)$ & $356(74.8 \%)$ & \\
\hline \multirow[t]{2}{*}{ Twin pregnancy } & Yes & $3(0.6 \%)$ & $7(1.5 \%)$ & $x^{2}=0.421(0.457)$ \\
\hline & No & $100(21 \%)$ & $366(76.9 \%)$ & \\
\hline \multicolumn{2}{|c|}{ Recent Hemoglobin level(just before delivery) } & $10.6( \pm 1.4)$ & $10.9( \pm 1.0)$ & $U=17433(0.208)$ \\
\hline \multicolumn{2}{|c|}{ BMI (just before delivery) } & $22.6( \pm 3.1)$ & $22.3( \pm 4.0)$ & $U=18179.5(0.405)$ \\
\hline \multicolumn{2}{|l|}{ APGAR score at 1 minute } & $7.9( \pm 0.5)$ & $7.9( \pm 0.4)$ & $U=17785(0.700)$ \\
\hline \multicolumn{2}{|l|}{ APGAR score at 5 minutes } & $8.9( \pm 0.5)$ & $8.9( \pm 0.4)$ & $U=17954(0.887)$ \\
\hline \multicolumn{2}{|l|}{ Baby's weight at birth } & $2.7( \pm 0.5)$ & $2.8( \pm 0.4)$ & $U=18557.5(0.747)$ \\
\hline \multirow[t]{2}{*}{ Illness in infant } & Yes & $4(0.8 \%)$ & $26(5.5 \%)$ & $x^{2}=1.315(0.251)$ \\
\hline & No & $99(20.8 \%)$ & $346(72.8 \%)$ & \\
\hline \multirow[t]{2}{*}{ Gender of infant } & Male & $53(11.1 \%)$ & $169(35.5 \%)$ & $x^{2}=1.226(0.268)$ \\
\hline & Female & $50(10.5 \%)$ & $204(42.9 \%)$ & \\
\hline EPDS Score baseline & & $10.2( \pm 4.0)$ & $10.4( \pm 3.8)$ & $t=0.543(0.588)$ \\
\hline \multirow{2}{*}{$\begin{array}{l}\text { EPDS Score above cut-off at } \\
\text { baseline }\end{array}$} & Yes & $73(15.4 \%)$ & $243(51.2 \%)$ & $x^{2}=1.186(0.276)$ \\
\hline & No & $30(6.3 \%)$ & $130(27.3 \%)$ & \\
\hline
\end{tabular}

Shown as mean ( \pm standard deviation) or frequency (percentages), BMI Body Mass Index, EPDS Edinburgh Postnatal Depression Scale 
Table 3: Comparison of those with depressive symptoms and those without depressive symptoms who came at follow up ( $N=103)$

\begin{tabular}{|c|c|c|c|c|}
\hline Variable & & $\begin{array}{l}\text { Depressive symptoms } \\
\text { present above cut-off at } \\
6 \text { week follow up } \\
(\mathrm{N}=62)\end{array}$ & $\begin{array}{l}\text { Depressive symptoms } \\
\text { not present above cut-off } \\
\text { at } 6 \text { week follow up } \\
(\mathrm{N}=41)\end{array}$ & Comparison (significance) \\
\hline Age & & $23( \pm 2.7)$ & $23( \pm 2.8)$ & $U=1258(0.930)$ \\
\hline \multirow[t]{2}{*}{ Education } & Up to High school & $44(42.7 \%)$ & $27(26.2 \%)$ & $x^{2}=0.301(0.583)$ \\
\hline & Above & $18(17.5 \%)$ & $14(13.6 \%)$ & \\
\hline \multirow[t]{2}{*}{ Employment } & Employed & $9(8.7 \%)$ & $5(4.9 \%)$ & $x^{2}=0.113(0.737)$ \\
\hline & $\begin{array}{l}\text { Not employed/ } \\
\text { homemaker }\end{array}$ & $53(51.5 \%)$ & $36(35 \%)$ & \\
\hline \multirow[t]{2}{*}{ Parity } & Primipara & $41(39.8 \%)$ & $27(26.2 \%)$ & $x^{2}=0.001(0.977)$ \\
\hline & Multipara & $21(20.4 \%)$ & $14(13.6 \%)$ & \\
\hline \multirow[t]{2}{*}{ Mode of delivery } & Vaginal & $61(59.2 \%)$ & $40(38.8 \%)$ & $x^{2}=0.088(1.000)$ \\
\hline & Caesarean & $1(1.0 \%)$ & $1(1.0 \%)$ & \\
\hline \multirow[t]{2}{*}{ Difficult pregnancy } & Yes & $0(0 \%)$ & $3(2.9 \%)$ & $x^{2}=4.673(0.060)$ \\
\hline & No & $62(60.2 \%)$ & $38(36.9 \%)$ & \\
\hline \multirow[t]{2}{*}{ Twin pregnancy } & Yes & $1(1 \%)$ & $2(1.9 \%)$ & $x^{2}=0.930(0.262)$ \\
\hline & No & $61(59.2 \%)$ & $39(37.9 \%)$ & \\
\hline \multicolumn{2}{|c|}{ Recent Hemoglobin level(just before delivery) } & $10.9( \pm 1)$ & $10.9( \pm 1)$ & $U=1192(0.741)$ \\
\hline \multicolumn{2}{|c|}{ BMI(just before delivery) } & $22.5( \pm 4.5)$ & $22( \pm 2.9)$ & $U=1116.5(0.298)$ \\
\hline \multicolumn{2}{|l|}{ APGAR score at 1 minute } & $7.9( \pm 0.5)$ & $7.9( \pm 0.2)$ & $U=1113(0.276)$ \\
\hline \multicolumn{2}{|l|}{ APGAR score at 5 minutes } & $8.9( \pm 0.4)$ & $8.9( \pm 0.2)$ & $U=1112(0.270)$ \\
\hline \multicolumn{2}{|l|}{ Baby's weight at birth } & $2.7( \pm 0.5)$ & $2.8( \pm 0.4)$ & $\mathrm{t}=1.205(0.131)$ \\
\hline \multirow[t]{2}{*}{ Illness in infant } & Yes & $2(1.9 \%)$ & $2(1.9 \%)$ & $x^{2}=0.180(1.000)$ \\
\hline & No & $60(58.3 \%)$ & $39(37.9 \%)$ & \\
\hline \multirow[t]{2}{*}{ Gender of infant } & Male & $31(30.1 \%)$ & $22(21.4 \%)$ & $x^{2}=0.132(0.716)$ \\
\hline & Female & $31(30.1 \%)$ & $19(18.4 \%)$ & \\
\hline \multirow[t]{2}{*}{$\begin{array}{l}\text { EPDS Score above cut-off at } \\
\text { baseline }\end{array}$} & Yes & $59(57.3 \%)$ & $14(13.6 \%)$ & $x^{2}=44.508(<0.001)^{*}$ \\
\hline & No & $3(2.9 \%)$ & $27(26.2 \%)$ & \\
\hline
\end{tabular}


Table 4: Logistic regression analysis results

\begin{tabular}{|c|c|c|c|c|c|}
\hline \multicolumn{6}{|c|}{ Predictors of depression at baseline $(N=476)$} \\
\hline Variables & $\mathrm{B}$ & $\operatorname{Exp}(B)$ & Odds ratio (Wald) & Significance & CI for $\operatorname{Exp}(B)$ \\
\hline Weight of the baby & -0.573 & 0.564 & 5.769 & 0.016 & 0.161 to 0.658 \\
\hline APGAR score at 1 minute & -1.124 & 0.325 & 9.757 & 0.002 & 0.297 to 0.919 \\
\hline Employed & -0.649 & 0.523 & 5.082 & 0.024 & 0.353 to 0.900 \\
\hline \multicolumn{6}{|c|}{ Model characteristics: Nagelkerke $\mathrm{R}^{2}=0.084$, Correct classification $=68.3 \%$} \\
\hline \multicolumn{6}{|c|}{ Predictors of follow up $(\mathrm{N}=476)$} \\
\hline Variables & B & Exp (B) & Odds ratio (Wald) & Significance & CI for $\operatorname{Exp}(B)$ \\
\hline Hemoglobin level of mother & 0.206 & 1.229 & 4.713 & 0.030 & 1.020 to 1.481 \\
\hline \multicolumn{6}{|c|}{ Model characteristics: Nagelkerke $\mathrm{R}^{2}=0.017$, Correct classification $=78.4 \%$} \\
\hline \multicolumn{6}{|c|}{ Predictors of depression at follow up $(\mathrm{N}=103)$} \\
\hline Variables & B & Exp (B) & Odds ratio (Wald) & Significance & CI for $\operatorname{Exp}(B)$ \\
\hline $\begin{array}{l}\text { Depressive symptoms at } \\
\text { baseline }\end{array}$ & 0.766 & 2.151 & 23.413 & $<0.001$ & 1.577 to 2.934 \\
\hline
\end{tabular}

